\title{
Robusta Extract Cream Ameliorated Ultraviolet B-induced Wrinkle Skin of Mice by the Regulation of Epidermal Thickness and Inhibition of MMP-1
}

\author{
Dimpuulina Erna Mariati ${ }^{1}$, Sunarjati Sudigdoadi ${ }^{1,2}$, Ronny Lesmana ${ }^{1,3,4}$, Astrid Feinisa Khairani ${ }^{5}$, \\ Julia Windi Gunadi ${ }^{6}$, Vita Murniati Tarawan ${ }^{1,3}$, Unang Supratman ${ }^{7}$, Hanna Goenawan ${ }^{1,3,4, *}$ \\ ${ }^{1}$ Magister Program of Anti Aging, Faculty of Medicine, Universitas Padjadjaran, Jl. Raya Bandung Sumedang KM 21, Jatinangor 45363, Indonesia \\ ${ }^{2}$ Microbiology Division, Department of Biomedical Science, Faculty of Medicine, Universitas Padjadjaran, Jl. Raya Bandung Sumedang KM 21, \\ Jatinangor 45363, Indonesia \\ ${ }^{3}$ Physiology Division, Department of Biomedical Science, Faculty of Medicine, Universitas Padjadjaran, Jl. Raya Bandung Sumedang KM 21, \\ Jatinangor 45363, Indonesia \\ ${ }^{4}$ Physiology Molecular Laboratory, Biological Activity Division, Central Laboratory, Universitas Padjadjaran, J1. Raya Bandung Sumedang KM 21 , \\ Jatinangor 45363, Indonesia \\ ${ }^{5}$ Cell Biology Division, Department of Biomedical Science, Faculty of Medicine, Universitas Padjadjaran, Jl. Raya Bandung Sumedang KM 21, \\ Jatinangor 45363, Indonesia \\ ${ }^{6}$ Department of Physiology, Faculty of Medicine, Maranatha Christian University, Jl. Profesor drg. Suria Sumantri, M.P.H. No. 65, Bandung 40164, \\ Indonesia \\ ${ }^{7}$ Department of Chemistry, Faculty of Mathematics and Natural Sciences, Universitas Padjadjaran, Jl. Raya Bandung Sumedang KM 21, \\ Jatinangor 45363, Indonesia \\ *Corresponding author. E-mail: hanna@unpad.ac.id
}

Received date: Oct 19, 2020; Revised date: Jan 4, 2021; Accepted date: Jan 7, 2021

\section{Abstract}

B ACKGROUND: Recently, coffee is widely used for preventing photoaging because of its antioxidant capacity. Among two kinds of coffee, robusta coffee has higher content of antioxidant such as chlorogenic acid (CGA) and caffeine. Researchs about robusta coffee bean effect on photoaging due to UVB radiation is still limited. Therefore, the aim of this study was to examine the effect of robusta extract cream (RE cream) on preventing wrinkle in mice induced by ultraviolet-B (UVB) radiation.

METHODS: RE cream was made by mixing RE coffee with moisturizing cream in different concentration $(10 \%$, $20 \%$, and $40 \%$ ). Twenty-five male of Mus musculus Balb/c strain mice aged 4 weeks were divided into five groups; control group, UVB group, UVB $+10 \%$ RE group, UVB $+20 \%$ RE group, and UVB $+40 \%$ RE group. The UVB groups were given UVB radiation three times a week with an exposure duration of 100 seconds per time for ten weeks. At the end of the treatment, skin samples were excised and statined histologically, also were analyzed for their protein expression. Evaluation of wrinkles was carried out using the Bissete method before and after treatment. To evaluate the thickness of the epidermis, HE staining was performed, while masson Trichome staining was performed to determine the collagen content.

RESULTS: RE cream-treated groups showed lower wrinkle score compared to the control group. Furthermore, in $\mathrm{UVB}+10 \% \mathrm{RE}$ group, the RE cream application reduce wrinkle formation. In UVB $+10 \% \mathrm{RE}$ group and $\mathrm{UVB}+20 \% \mathrm{RE}$ group, the RE cream application increased epidermal thickness and collagen content $(p=0.00)$. While collagenase, matrix metalloproteinase-1 (MMP-1) expression was lower in UVB $+20 \%$ RE group compared to the UVB group $(p<0.05)$, however the MMP1 expression in UVB $+40 \%$ RE group was higher than other treatment group.

CONCLUSION: RE cream prevents wrinkle by maintaining epidermal thickness and collagen contain. RE cream also decreases MMP-1 expression in mice.

KEYWORDS: coffee, collagen, MMP-1, robusta, wrinkle

Indones Biomed J. 2021; 13(1): 84-90 


\section{Introduction}

The skin is one of the largest organ of human body. Skin has a lot of function such as first barrier against pathogens, chemicals, protecting against damage and from ultraviolet (UV).(1) Skin aging is a loss of skin components which is characterized by a decrease in skin elasticity, pigmentation, or loss of skin cell barrier on the epidermis layer.(2) Premature skin aging (photoaging) can be caused by chronic sunray exposure. $(3,4)$ Sunray radiation contains UVA and UVB radiation. Although small amount of UVB exposure, its intensity can cause photoaging.(5) Chronic UVB radiation induces degradation of skin structure such as proinflamatory cytokines such as interleukin (IL)-1 $\alpha$, and activate matrix metalloproteinase (MMP) in skin cells such as keratinocytes and fibroblast.(6)

Reactive oxygen species (ROS) affect DNA and decreased tyrosine phosphatase cause increase of MMP production and decrease collagen production.(6) MMP degraded collagen type I with hydrolysis reaction.(7) Low collagen structure in skin cause wrinkle formation. Wrinkle formation shown by histology examination provides characteristics like changes in epidermal thickness and collagen formation.(8)

Coffee is one popular drinks worldwide, every years approximately seven tons coffee consumed by people all over the world.(9) Coffee contains not only chlorogenic acids (CGA) and their derivatives, but also caffeine, theophylline and theobromine, cafestol, kahweol, tocopherols and trigonelline, which have huge benefit for health.(10) Robusta coffee has higher antiradical capacity compared to arabica coffee. CGA and caffeine is highly expressed in robusta coffee.(11) CGA has been reported as an antioxidant and anti-inflammation that could prevent protoaging by decreasing free radicals.(12,13) It has been reported that coffee components prevent photoaging by decreasing MMP expression.(14)

However, there is limited information about protective effect of robusta extract (RE) cream for photoaging in mice. Therefore, we are interested to investigate RE cream effect to prevent wrinkle in skin of UVB treated mice.

\section{Methods}

\section{Animal Experiment}

Twenty-five ales of Mus musculus Balb/c strain mice aged 4 weeks, weight $25 \pm 5$ gr were used in this experiment.
Animals were kept under a controlled room temperature and photoperiodicity of 12-hours light/dark system in Department of Pharmacology and Therapy, Universitas Padjadjaran, Jatinangor. Mice were acclimatized for 7 days and randomly divided into five groups, which were control group, UVB group, UVB $+10 \%$ RE group, UVB $+20 \%$ $\mathrm{RE}$ group, and UVB $+40 \% \mathrm{RE}$ group. All procedure were approved by the Ethical Committee, Universitas Padjadjaran (No.: 1163/UN6.KEP/EC/2019).

\section{RE Cream Extraction}

Robusta coffee beans were obtained from Lampung, Indonesia. Robusta coffee beans were extracted using maseration method. Coffee bean was mashed and then soak in $70 \%$ ethanol for three days. We filtered the sample, and we evaporated the filtrate using rotary evaporator until it goy extracted. We kept the extract until the ethanol evaporated. Then, the extract were mixed with vanishing cream contain vaseline, stearic acid, wax, triethanolamine, and propylene glycol into three different concentration $(10 \%, 20 \%$, and $40 \%) .(15)$

\section{UV Irradiation and RE Cream Treatment}

Mice were exposed to UV light (kernel KN-4003) at a dose of $166 \mathrm{~mJ} / \mathrm{cm}^{2}$ three times a week for teen weeks and the duration of each exposure was 100 seconds. The distance between the UV light and the skin was $3 \mathrm{~cm}$.(16) During the experiment each mice were irradiated at different cage. After the irradiation, mice were returned to standard cage to get access for food and drink ad libitum.

As much as $0.1 \mathrm{~g} / \mathrm{cm}^{2} \mathrm{RE}$ cream in different concentration were applied on the back skin of mice. RE cream was applied after UVB exposure once a day, for ten weeks.

\section{Wrinkle Assessment}

After shaving, the wrinkles on the back skin of the mice were photographed before and after the experimental period. The assessment of wrinkles were done based on the Bissette method.(17)

We divided wrinkle by grading. Grade 0 : numerous fine striations covering back and flanks of body, fine striations ran length of body and appear and disappear with motion. Grade 1: all fine striations on back along spine were gone, a few shallow coarse wrinkles across back which appear and disappear with motion. Grade 2: all fine striations were gone, some coarse wrinkles across back which were permanent. Grade 3: all fine striations were gone, several deep coarse wrinkles across back which were permanent. 


\section{Protein Extraction and Western Blotting}

Twenty-four hours after the last UVB exposure, mice were sacrificed with ketamine injection, and skin samples were excised in back area with size $2 \times 3 \mathrm{~cm}^{2}$. Skin samples was stored at $-80^{\circ} \mathrm{C}$ for western blot analysis and kept in $10 \%$ formalin at room temperature for Haematoxylin-Eosin (HE) and Masson Thrichome staining. Protein were isolated using RIPA (20 mM Tris- $\mathrm{HCl} \mathrm{pH} 7.5,150 \mathrm{mM} \mathrm{NaCl}$, 1 mM Na2EDTA; 1 mM EGTA; 1\% NP-40; 1\% sodium deoxycholate; $2.5 \mathrm{mM}$ sodium pyrophosphate; $1 \mathrm{mM}$ $\beta$-glycerophosphate; $1 \mathrm{mM} \mathrm{Na} 3 \mathrm{VO} 4 ; 1 \mathrm{ug} / \mathrm{mL}$ leupeptin) as previously described.(16) Protease inhibitor coctail $1 \mathrm{mM}$ (Merck KGA, Darmstadt, Germany) were added to inhibit proteolysis. Protein lysate were taken from the supernatant after five minute centrifugation at $15.000 \mathrm{rpm}$ in $4^{\circ} \mathrm{C}$ temperature. Protein lysate were mixed with sample buffer (10 mM Tris- $\mathrm{HCl}$ (pH 7.8), $150 \mathrm{mM} \mathrm{NaCl}, 1 \mathrm{mM}$ EDTA, $1 \% \mathrm{P}-40$, and protease inhibitors) then heated in $95^{\circ} \mathrm{C}$ for five minutes. Next, protein sample equally resolved by TRIS-SDS page gel and transferred to nitrocellulose membranes.

Protein were blotted to nitrocellulose membrane (Merck Millipore, Burlington, MA, USA) with MiniBlot (Thermo Scientific Fisher, Waltham, MA, USA). Primary antibody MMP-1 (1:200; Thermo Fisher Scientific) and secondary antibody, anti Rabbit IR DYE 680 RD (1:5000; LI-COR Biosciences, Lincoln, NE, USA) were used for immunoblotted. We used anti GAPDH antibody (1:200, Thermo Fisher Scientific) to confirm protein equality. Membrane were visualized using Odyssey CLx Imaging System (LI-COR Biosciences). Band density were quantified using image J software (NIH, Bethesda, MD, USA).

\section{Histological Examination using HE and Masson Trichrome Staining}

Skin tissue were blocked using paraffin embeded block and cutted into $6 \mu \mathrm{m}$ slice. Slide were subjected to HE staining and Masson Trichrome staining for collagen dectection. Image were taken using light microscope Apotome 2 (Carl Zeiss GmBH, Jena, Germany) with 400x magnification. Epidermal thickness were measured using image analysis software ZEN pro (Carl Zeiss GmBH) for H\&E staining. Mean of epidermal thickness were measured at 5 different sites for each subjects.

\section{Statistical Analysis}

All statistical analysis data were presented as mean \pm standard deviation (SD). Wrinkle score data were not distributed normally and homogen. Thus, to analyze the difference between groups, Kruskal-wallis and Mann-Whitney test were used. Epidermal thickness data were normal and homogen. One-Way ANOVA test continue with the least significant difference (LSD) test were used to analyzed this datas.

\section{Results}

\section{Effect of RE Cream on Wrinkle Formation}

To study the effect of RE cream on wrinkle formation, we examined the wrinkle progression on mice skin. Results showed that wrinkle formation were reduced in RE group in dose dependent manner (Figure 1 A, Figure 2A). The lowest wrinkle score were observed in UVB $+10 \%$ RE group $(0.2$, $p<0.05)$. Wrinkle examination based on Bissette method showed that RE cream prevented wrinkle formation $(0.2$ for UVB $+10 \%$ RE group; 0.6 for UVB $+20 \%$ RE group; and 1.2 for UVB $+40 \%$ RE group) compared to control group (1.8 for UVB group) as shown in Figure 2A.

\section{RE Cream Increase Epidermal Thickness and Collagen Deposition in Photoaging Model Mice.}

We made skin preservation for histology examination using HE staining. Epidermal thickness were measured to evaluate the effect of RE cream on collagen destruction. To determine whether RE cream application maintain epidermis thickness, we measured epidermal thickness in skin histology. UVB exposure to the mice skin decreased the epidermal thickness as shown in Figure 1 B, Figure 2B.

Epidermal thickness in all groups treated with $\mathrm{RE}$ were significantly higher than UVB group $(p<0.05)$. However, no difference between the groups treated with RE cream was observed (Figure 2B). The result showed that RE cream increased epidermal thickness significantly (406 $\mu \mathrm{m}$ for UVB $+10 \%$ RE group; $460 \mu \mathrm{m}$ for UVB $+20 \% \mathrm{RE}$ group; and $381 \mu \mathrm{m}$ for UVB $+40 \%$ RE group) compared to control group (Figure 2B, Table 1). It suggest that epidermal thickness reduction in UVB exposure were ameliorated with RE treatment.

Photoaging induce imbalance of collagen synthesis and degradation. As the main structure in the extracellular matrix of the dermis, collagen degradation can be observes as wrinkle. To confirm the correlation between wrinkle level and collagen content in skin, we stained the skin histology samples with Masson Trichrome (Figure 1C). Collagen content were stained by blue colour (black arrow). UVB treated mice showed lower collagen content compared to the control group. 

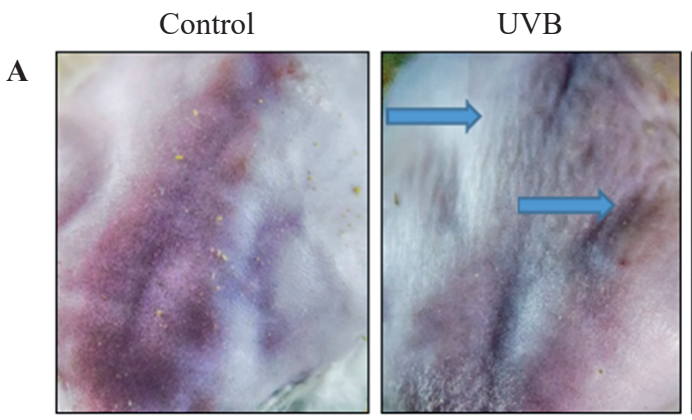

$\mathrm{UVB}+10 \% \mathrm{RE}$

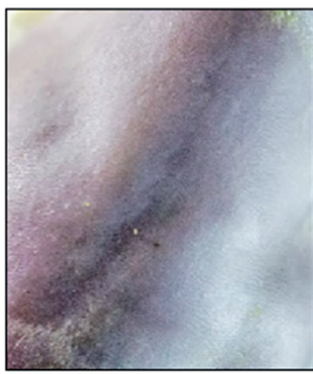

C
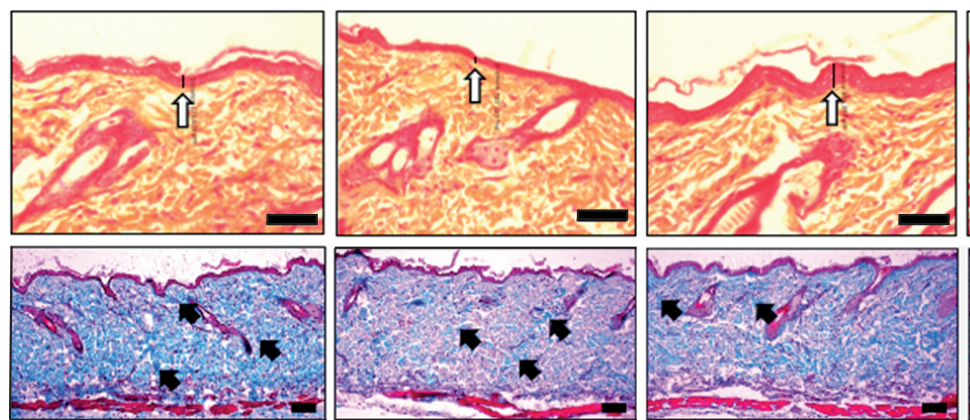

$\mathrm{UVB}+20 \% \mathrm{RE}$
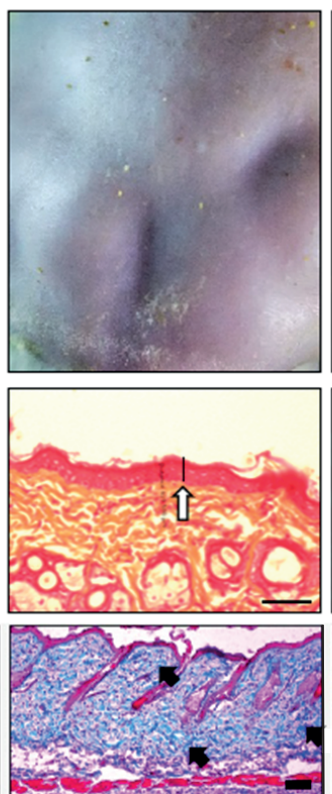

$\mathrm{UVB}+40 \% \mathrm{RE}$
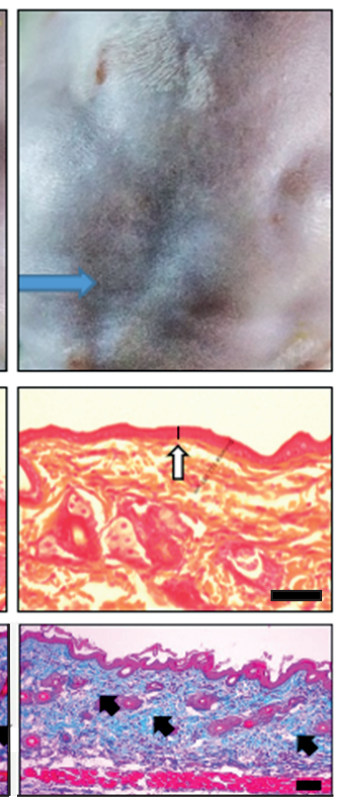

Figure 1. Observation on the mice's back skin. A: Wrinkle formation in mice skin (blue arrow: wrinkle). B: HE staining (white arrow: epidermal thickness; black bar: 1,000 $\mu \mathrm{m}$ ). C: Masson's Trichrome staining (black arrow: collagen deposition; black bar: 1,000 $\mu \mathrm{m}$ ).

\section{RE Cream Decreased MMP-1 Protein Expression}

To clarify whether delayed process of wrinkle production by RE cream was correlated with collagen destruction enzyme, we examined the MMP-1 protein expression. We found that RE cream application decreased MMP-1 protein expression in skin mice (Figure 3, Table 1).

After 10 weeks of treatment, MMP-1 protein expression significantly lower in UVB $+20 \%$ RE group $(0.92 \pm 0.12, p<0.05)$ compared to the UVB group $(1.92 \pm 0.63, p=0.025)$ as shown in Table 1 . However, UVB $+10 \% \mathrm{RE}$ group $(1.81 \pm 0.42)$ and $\mathrm{UBV}+40 \% \mathrm{RE}$ group $(1.52 \pm 0.33)$ did not show any changes in MMP-1 protein expression.

A.

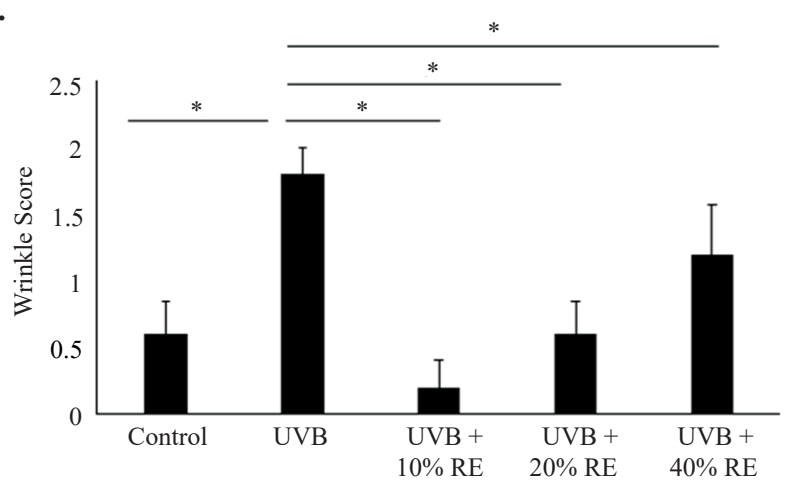

\section{Discussion}

UV radiation reported increase ROS production and could activated signal transduction and lead to decrease collagen synthesis. $(18,19)$ Wrinkle is one of photoaging sign with histological feature decrease epidermal thickness, and decreased collagen density.(20) Consistent with another studies, UVB irradiation on mice skin for 10 weeks induced skin wrinkle, decrease epidermal thickness and increase of MMP-1 expression.

Coffee was proposed to have a potent antioxidant capacity. Antioxidant capacity in coffee extract was

B.

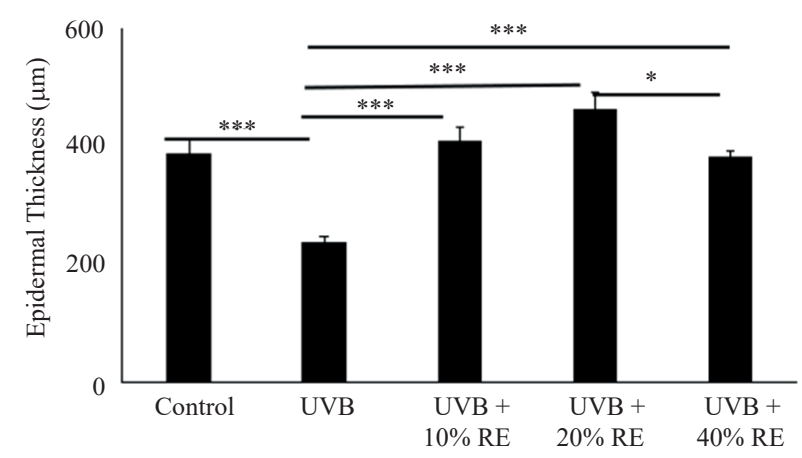

Figure 2. Effect of RE cream-on skin of photoaging mice. A: Quantification of wrinkle score. B: Epidermal thickness. Data were shown as mean \pm SEM. Asteriks indicated statistical significant, ${ }^{*} p<0.05 ; * * * p<0.001$. 
Table 1. Wrinkle Score, epidermal thickness, and quantification of western blot results.

\begin{tabular}{lccc}
\hline \multirow{2}{*}{ Group } & \multicolumn{3}{c}{ Mean \pm SD } \\
\cline { 2 - 4 } & Wrinkle Score & Epidermal Thickness & MMP-1 Protein Expression \\
\hline Control & $0.60 \pm 0.55$ & $390.79 \pm 47.04$ & $1.439 \pm 0.310$ \\
UVB & $1.80 \pm 0.45$ & $237.63 \pm 23.10$ & $1.923 \pm 0.630$ \\
UVB $+10 \%$ RE & $0.20 \pm 0.45$ & $406.99 \pm 53.22$ & $1.812 \pm 0.452$ \\
UVB $+20 \%$ RE & $0.60 \pm 0.55$ & $460.49 \pm 68.50$ & $0.924 \pm 0.127$ \\
UVB $+40 \%$ RE & $1.20 \pm 0.84$ & $381.81 \pm 23.73$ & $1.527 \pm 0.334$ \\
\hline
\end{tabular}

obtained from its high polyphenol concentration including CGA. Research reported that Robusta coffee contains higher polyphenol than Arabica coffee.(21-24) CGA also found higher in robusta coffee compared to arabica coffee.(11) In the present study, we found that topical application of robusta coffee cream inhibit wrinkle by maintain epidermal thickness (Figure 1B, Figure D) and collagen fibrils deposition (Figure 1C) in UVB treated mice.

CGA prevent photoaging through the mitogen activated protein kinase (MAPK) pathway.(21) MAPK could activated regulator protein such as extracellular signal-regulated kinases (ERK), c-Jun N-terminal kinase (JNK) and p38. This protein could increase activator protein 1 (AP-1) expression which is a transcription factor that could inhibit pro collagen gene expression. AP-1 and nuclear factor kappa-B (NF- $\kappa \mathrm{B})$ activation increase MMP1 expression.(25) MMP-1, one of collagenase family, responsible for initiation of collagen fragmentation.(26) MMP-1 degradate collagen type I and III.(26) Further

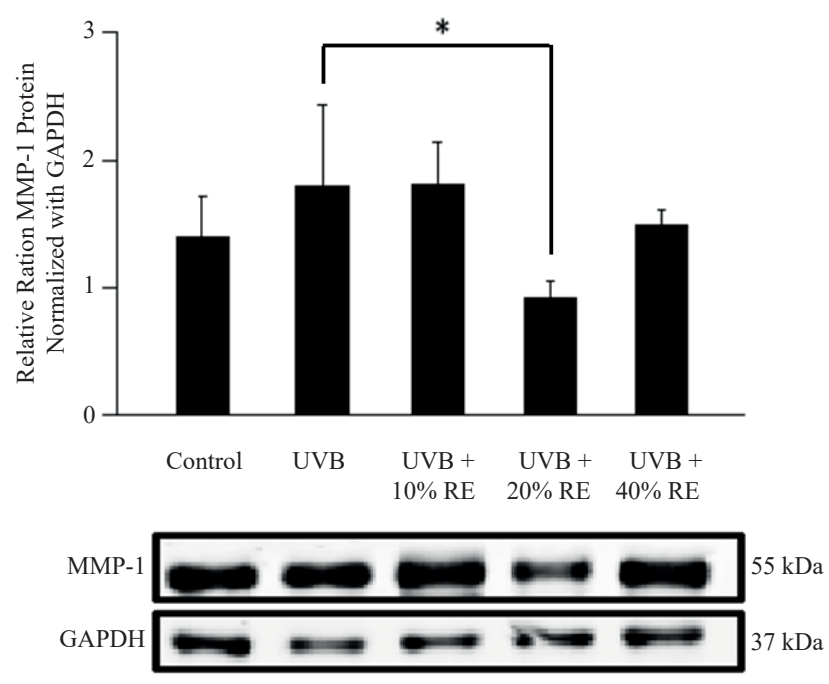

Figure 3. MMP-1 protein expression on skin sample of photoaging mice.UVB mice expressed high MMP-1 protein, RE cream treatment suppressed MMP-1 protein expression. Data represent mean $\pm \mathrm{SEM}$. Asteriks indicated statistical significant, $* p<0.05$. degradation of collagen were done by MMP-3 and MMP9. Sequester of collagen may inhibit procollagen synthesis. Function changes in aged skin such as loss of elasticity and wrinkle formation because the number of functional elastic fibers is reduced.(27) Our study revealed that RE cream could decrease MMP-1 expression and maintain collagen content in dermis. Therefore, wrinkle as symptoms of photoaging process could be prevented. Figure 4 shows the mechanism of RE cream on skin photoaging process.

We observed that RE cream were suppress MMP1 expression in dose dependent manner. Only UVB +20 $\mathrm{RE}$ group showed significant reduction on MMP-1 protein expression. While slight reduction was observed on UVB + $10 \% \mathrm{RE}$ and UVB $+40 \% \mathrm{RE}$ groups. Discrepancies found in MMP-1 potein expression and epidermal thickness possibly caused by another MMPs expression. Administration of $0.5 \%$ oral coffee ground extract had better potential for photoaging prevention by supressing MMP-2, 9, 14.(28) Thus, in the future, correlation between dose dependent $\mathrm{RE}$ cream and MMPs expression is need to be studied. Furhermore, caffeine content in RE may contribute to decrease ROS production through enchance superoxide dismutase 2 (SOD2) activity.(29)

RE contains several bioactive compound such as caffeine, CGA, and phenolic acid. High CGA content may contribute to oxidative stress. Studies in mice endothelial cells using high CGA and phenolic acid injection showed increased production of ROS in venular wall.(30) However, in this study, we did not identify the bioactive compound in RE cream. We observed less effect of RE treatment on higher concentration of RE cream (40\%). Possibly, higher concentration in RE group (40\%) lead to imbalance between oxidant and antioxidant. Hence, futher study to evaluated the CGA content in RE cream and its effect on ROS production in skin needs to be conducted.

Natural sources such as Nypa fruticans, has similar effect coffee ground extract. Study using Nypa fruticans showed inhibition of MMP-1 and increase collagen synthesis. Increase epidermal thickness and less wrinkle 


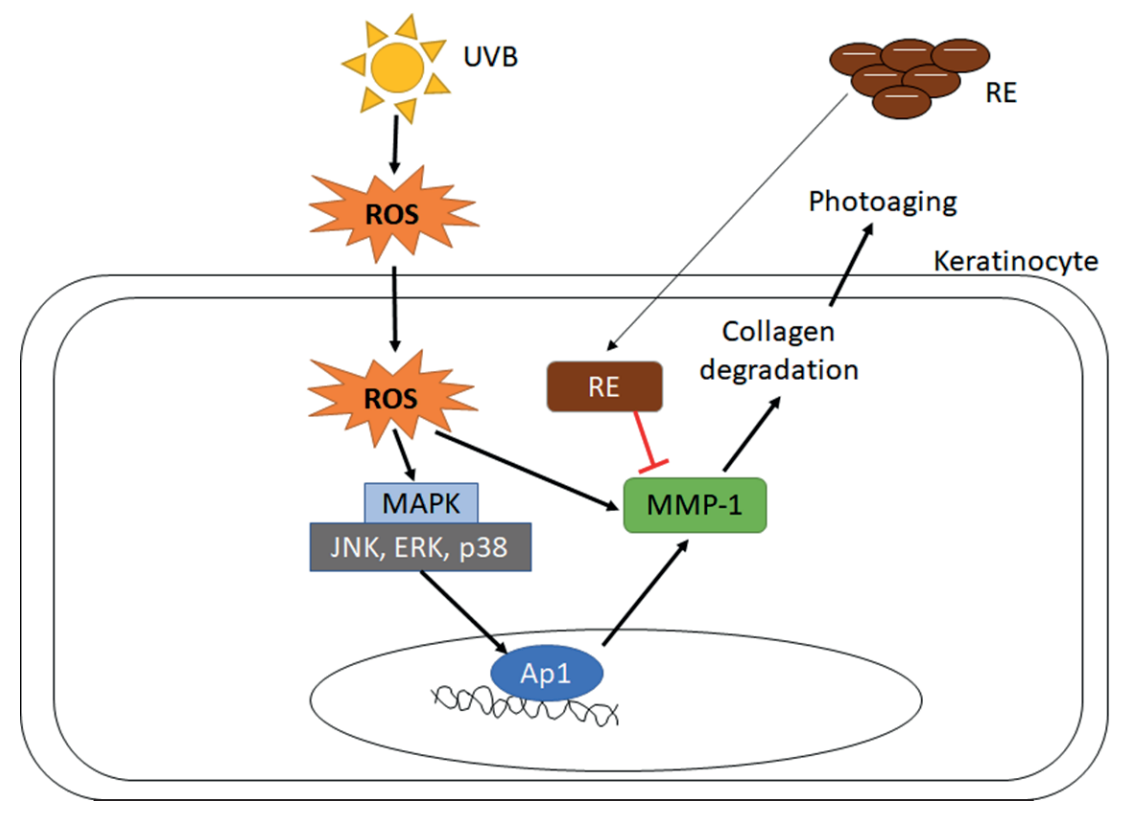

Figure 4. Purpose mechanism of RE on skin photoaging process. UVB induce ROS production and activate MAPK pathway. MAPK take central role in activation mitogen; JNK, ERK and p38 and lead to increase of MMP-1 expression. MMP-1 takes role in collagen degradation thus decrease epidermal thickness and increase wrinkle formation. ER suppress MMP-1 protein expression and ameliorated wrinkle progression in photoaging mice. also observed in Nypa fruticans treatment. Nypa fruticans was contains protocathechuic acid, catechin, CGA, and another polyphenolics. Therefore, another natural product contain CGA effect on skin photoaging must be evaluated.

\section{Conclusion}

Our study revealed that RE cream prevent photoaging skin in UVB treated Balb/C mice in dose dependent manner partly through suppression of MMP-1. However, lower dose $(10 \%$ and $20 \%)$ of RE cream showed preferable antiphotoaging effect. While $40 \%$ RE did not showed any significant changes on epidermal thickness possibly due to oxidative stress.

\section{Acknowledgements}

The authors are thankful to Susianti, Nurul Ihsani and Canadia from Central Laboratory UNPAD for technical assistance during experiments.

This study was funded by Internal Research Grant/ Hibah Internal Universitas Padjadjaran (No. 1427/UN6.3.1/ $\mathrm{LT} / 2020$ ).

\section{Authors Contribution}

DEM and HG were involved in concepting and designing the study. DEM, HG, RL, and US were involved in the experiment. AFK provided the data analysis. SS, RL, VMT performed the statistical analysis. DEM, HG, and VMT wrote and edited the manuscript. Meanwhile JWG helped in reviewing the manuscript.

\section{References}

1. Hani Y, Sharma S. Anatomy, Skin (Integument), Epidermis. In: StatPearls. Treasure Island (FL): StatPearls Publishing LLC; 2019. p.1-12.

2. Panich U, Sittithumcharee G, Rathviboon N, Jirawatnotai S. Ultraviolet radiation-induced skin aging: the role of DNA damage and oxidative stress in epidermal stem cell damage mediated skin aging. Stem Cells Int. 2016; 2016: 7370642. doi: 10.1155/2016/7370642.

3. Addor F. Beyond photoaging: additional factors involved in the process of skin aging. Clin Cosmet Investig Dermatol. 2018; 11: 437-43.

4. Shanbhag S, Nayak A, Narayan R, Nayak UY. Anti-aging and Sunscreens : Paradigm Shift in Cosmetics. Adv Pharm Bull. 2019; 9: 348-59.

5. Pittayapruek P, Meephansan J, Prapapan O, Komine M, Ohtsuki M. Role of matrix metalloproteinases in Photoaging and photocarcinogenesis. Int J Mol Sci. 2016; 17: 868. doi: 10.3390/ ijms 17060868 .

6. Liebel F, Kaur S, Ruvolo E, Kollias N, Southall MD. Irradiation of skin with visible light induces reactive oxygen species and matrixdegrading enzymes. J Invest Dermatol. 2012; 132: 1901-7.

7. Han S, Makareeva E, Kuznetsova NV., DeRidder AM, Sutter MB, Losert W, et al. Molecular mechanism of type I collagen homotrimer resistance to mammalian collagenases. J Biol Chem. 2010; 285: 22276-81.

8. Rahunen K, Rieppo L, Lehenkari P, Finnilä M, Saarakkala S. Evaluation of quantitativity of histological collagen stains in articular cartilage. Osteoarthr Cartil. 2016; 24: S307-8. 
9. Garg SK. Green coffee bean. Nutraceuticals Effic Saf Toxic. 2016; 62: 653-67.

10. Jeszka-Skowron M, Sentkowska A, Pyrzyńska K, De Peña MP. Chlorogenic acids, caffeine content and antioxidant properties of green coffee extracts: influence of green coffee bean preparation. Eur Food Res Technol. 2016; 242: 1403-9.

11. Bessada SMF, Alves RC, Oliveira BPP. Coffee silverskin: A review on potential cosmetic applications. Cosmetics. 2018; 5: 5. doi: 10.3390/cosmetics5010005.

12. Tajik N, Tajik M, Mack I, Enck P. The potential effects of chlorogenic acid, the main phenolic components in coffee, on health: a comprehensive review of the literature. Eur J Nutr. 2017; 56: 221544.

13. Liang N, Kitts DD. Role of chlorogenic acids in controlling oxidative and inflammatory stress conditions. Nutrients. 2015; 8: 16. doi: 10.3390/nu8010016.

14. Choi HS, Park ED, Park Y, Suh HJ. Spent coffee ground extract suppresses ultraviolet B-induced photoaging in hairless mice. J Photochem Photobiol B Biol. 2015; 153: 164-72.

15. Pergolizzi S, D’Angelo V, Aragona M, Dugo P, Cacciola F, Capillo $\mathrm{G}$, et al. Evaluation of antioxidant and anti-inflammatory activity of green coffee beans methanolic extract in rat skin. Nat Prod Res. 2018; 34: 1535-1541.

16. Eltania F, Lesmana R, Sudigdoadi S, Sudigdoadi S, Khairani AF, Goenawan $\mathrm{H}$, et al. Tranexamic acid cream protects ultraviolet B-induced photoaging in Balb/c mice skin by increasing mitochondrial markers: changes lead to improvement of histological appearance. Photochem Photobiol. 2020; 96: 863-9.

17. Bissett DL, Hannon DP, Orr T V. An animal model of solar-aged skin: histological, physical, and visible changes in UV-irradiated hairless mouse skin. Photochem Photobiol. 1987; 46: 367-78.

18. Chiu HW, Chen CH, Chen YJ, Hsu YH. Far-infrared suppresses skin photoaging in ultraviolet B-exposed fibroblasts and hairless mice. PLoS One. 2017; 12: 1-15.

19. Yin R, Chen Q, Hamblin MR, Yin R. Skin aging and photoaging. In: Skin photoaging. San Rafael, CA: Morgan \& Claypool Publishers; 2015. p.1-4.
20. Debacq-Chainiaux F, Leduc C, Verbeke A, Toussaint O. UV, stress and aging. Dermatoendocrinol. 2012; 4: 236-40.

21. Chiang HM, Lin TJ, Chiu CY, Chang CW, Hsu KC, Fan PC, et al. Coffea arabica extract and its constituents prevent photoaging by suppressing MMPs expression and MAP kinase pathway. Food Chem Toxicol. 2011; 49: 309-18.

22. Dias R, Benassi M. Discrimination between arabica and robusta coffees using hydrosoluble compounds: is the efficiency of the parameters dependent on the roast degree? Beverages. 2015; 1: 12739.

23. Fukagawa S, Haramizu S, Sasaoka S, Yasuda Y, Tsujimura H, Murase T. Coffee polyphenols extracted from green coffee beans improve skin properties and microcirculatory function. Biosci Biotechnol Biochem. 2017; 81: 1814-22.

24. Stefanello N, Spanevello RM, Passamonti S, Porciúncula L, Bonan $\mathrm{CD}$, Olabiyi AA, et al. Coffee, caffeine, chlorogenic acid, and the purinergic system. Food Chem Toxicol. 2019; 123: 298-313.

25. Tanaka K, Asamitsu K, Uranishi H, Iddamalgoda A, Ito K, Kojima $\mathrm{H}$, et al. Protecting skin photoaging by NF- $\mathrm{kB}$ inhibitor. Curr Drug Metab. 2010; 11: 431-5.

26. Freitas-Rodríguez S, Folgueras AR, López-Otín C. The role of matrix metalloproteinases in aging: Tissue remodeling and beyond. Biochim Biophys Acta - Mol Cell Res. 2017; 1864: 2015-25.

27. Shin JW, Kwon SH, Choi JY, Na JI, Huh CH, Choi HR, et al. Molecular mechanisms of dermal aging and antiaging approaches. Int J Mol Sci. 2019; 20: 2126. doi: 10.3390/ijms20092126.

28. Choi HS, Park ED, Park Y, Han SH, Hong KB, Suh HJ. Topical application of spent coffee ground extracts protects skin from ultraviolet B-induced photoaging in hairless mice. Photochem Photobiol Sci. 2016; 15: 779-90.

29. Choi HJ, Alam MB, Baek ME, Kwon YG, Lim JY, Lee SH. Protection against UVB-Induced Photoaging by Nypa fruticans via Inhibition of MAPK/AP-1/MMP-1 Signaling. Oxid Med Cell Longev. 2020; 2020: 2905362. doi: 10.1155/2020/2905362.

30. Du WY, Xiao Y, Yao JJ, Hao Z, Zhao YB. Involvement of NADPH oxidase in high-dose phenolic acid-induced pro-oxidant activity on rat mesenteric venules. Exp Ther Med. 2017; 13: 17-22. 